\title{
Correlation Between Gastric Emptying and Gastric Adaptive Relaxation Influenced by Amino Acids
}

\author{
Masayuki Uchida, Orie Kobayashi, ${ }^{*}$ and Chizuru Saito \\ Food Science Research Laboratories, Research and Development Division, Meiji Co, Ltd, Odawara, Kanagawa, Japan
}

\section{Background/Aims}

Amino acids have many physiological activities. We report the correlation between gastric emptying and gastric adaptive relaxation using tryptophan and amino acids with a straight alkyl chain, hydroxylated chain, and branched chain. Here we sought to further clarify the correlation between gastric emptying and gastric adaptive relaxation by using other amino acids.

\section{Methods}

In Sprague-Dawley rats, gastric emptying was evaluated by a breath test using $\left[1{ }^{13} \mathrm{C}\right]$ acetic acid. The expired ${ }^{13} \mathrm{CO}_{2}$ pattern, $\mathrm{T}_{\max }, \mathrm{C}_{\max ,}$ and $\mathrm{AUC}_{120 \mathrm{~min}}$ values were used as evaluation items. Gastric adaptive relaxation was evaluated in a barostat experiment. Individual amino acids $(1 \mathrm{~g} / \mathrm{kg})$ were administered orally 30 minutes before each breath test or barostat test.

\section{Results}

L-phenylalanine and L-tyrosine did not influence gastric emptying. All other amino acids, ie, L-proline, L-histidine, L-cysteine, L-methionine, L-aspartic acid, L-glutamic acid, L-asparagine, L-arginine, L-glutamine, and L-lysine significantly delayed and inhibited gastric emptying. L-Cysteine and L-aspartic acid significantly enhanced and L-methionine and L-glutamine significantly inhibited gastric adaptive relaxation. L-Phenylalanine moved the balloon toward the antrum, suggesting strong contraction of the fundus. $T_{\max }$ showed a significant positive correlation $(r=0.709)$, and $C_{\max }$ and $A U C_{120 m i n}$ each showed negative correlations $(r=0.613$ and 0.667, respectively) with gastric adaptive relaxation.

\section{Conclusion}

From the above findings, it was found that a close correlation exists between gastric emptying and adaptive relaxation, suggesting that enhanced gastric adaptive relaxation inhibits gastric emptying.

(J Neurogastroenterol Motil 2017;23:400-408)

\section{Key Words}

Amino acids; Aspartic acid; Gastric emptying; Phenylalanine; Rats

Received: September 13, 2016 Revised: January 4, 2017 Accepted: January 15, 2107

(a) This is an Open Access article distributed under the terms of the Creative Commons Attribution Non-Commercial License (http://creativecommons. org/licenses/by-nc/4.0) which permits unrestricted non-commercial use, distribution, and reproduction in any medium, provided the original work is properly cited.

*Correspondence: Orie Kobayashi Food Science Research Laboratories, Research and Development Division, Meiji Co, Ltd, 540 Naruda, Odawara, Kanagawa 2500862, Japan Tel: +81-465-37-3664, Fax: +81-465-36-2776, E-mail: orie.kobayashi@meiji.com 


\section{Introduction}

Many physiological functions of amino acids have been reported. The physiological functions of $\mathrm{L}$-glutamic acid in particular have been studied because L-glutamic acid is present in most organs and tissues such as skeletal muscles, brain, kidneys, and liver, and it plays several important roles. ${ }^{1,2}$ A physiological role of dietary glutamic acid also has been reported. ${ }^{3}$ Regarding gastric function, the effects of essential and nonessential amino acids were evaluated on gastric emptying in dogs. ${ }^{4}$ In the other report, L-arginine, Llysine, and L-glutamic acid inhibited food intake via the area postrema or vagal afferents. ${ }^{5}$ In addition, a sense of fullness was greater after L-tryptophan treatment than after ingestion of D-tryptophan. ${ }^{6}$ These findings suggest that the above-mentioned amino acids inhibit gastric emptying.

We observed that amino acids with an alkyl chain, hydroxyl group, and branched chain differently inhibited and/or delayed gastric emptying as shown by a breath test, ${ }^{7}$ and that L-glycine and L-serine significantly enhanced gastric adaptive relaxation in a barostat study. ${ }^{8}$ Based on those findings, we speculated that there is a close correlation between gastric emptying and gastric adaptive relaxation. Indeed, another of our studies demonstrated that Ltryptophan significantly inhibited gastric emptying and significantly enhanced gastric adaptive relaxation. ${ }^{9}$ The delay of gastric emptying also reported to relate the gastric adaptive relaxation in proton pump inhibitor-treated patients, ${ }^{10}$ suggesting that the enhancement of gastric adaptive relaxation induces a delay of gastric emptying. In addition, the effect of pancreatic polypeptide was evaluated in gastric accommodation and gastric emptying in conscious rats. ${ }^{11}$ These findings are in accordance with our finding that the delay of gastric emptying is closely related to enhanced gastric adaptive relaxation. ${ }^{8,9}$

If there was amino acid enhancing or inhibiting gastric adaptive relaxation without significantly affecting gastric emptying, it would be useful material for treating functional dyspepsia, especially for early satiety or obesity and diabetic mellitus, respectively. Indeed, acotiamide is the only drug in the world for the treatment of functional dyspepsia ${ }^{12,13}$ and there is no therapeutic drug for the treatment of obesity.

Therefore, in the present study, to further clarify the correlation between gastric emptying and adaptive relaxation, we evaluated the effects of other cyclic amino acids, amino acids with an aromatic ring and a sulfur group, and acidic and basic amino acids on gastric emptying and adaptive relaxation in a rat model.

\section{Materials and Methods}

The following animal studies were performed in accordance with the Guiding Principles for the Care and Use of Laboratory Animals approved by Meiji Co., Ltd.

\section{Animals}

Male Sprague-Dawley rats (7-8 weeks old) were purchased from SLC (Hamamatsu, Japan) and housed for 1 week prior to commencement of experiments under a constant temperature of 21 $\pm 2{ }^{\circ} \mathrm{C}$, humidity of $55 \pm 15 \%$ and a 12-hour light/dark cycle (light from 7:00 to 19:00). The rats were fasted in mesh cages for 18 hours before each experiment in order to prevent coprophagy, but were allowed free access to drinking water during this period.

\section{Breath Test System}

The breath test was performed as previously described. ${ }^{14}$ In brief, desiccators were selected as the animal chambers because they were easy to set up. Each animal chamber was connected to an aspiration pump (Masterflex L/S; Cole-Parmer, Vernon Hills, IL, USA). A desiccator with a volume of $2000 \mathrm{~mL}$ was employed so that the rat could move freely within the chamber and the expired air could be collected effectively in the breath-sampling bag (Otsuka Pharmaceutical, Tokyo, Japan). Aspirating the expired air caused fresh air to be automatically drawn into the desiccator through a hole in the side of the desiccator. The air in the chamber was continuously aspirated during the experimental period. Aspirated air was discharged to the exterior of this breath test system except for the period during which expired air was collected in the breath-sampling bag. An infrared spectrometer (POCone; Otsuka Electronics, Osaka, Japan) was used to measure the expired ${ }^{13} \mathrm{CO}_{2}$ because it can do so simply and effectively.

\section{Test Meal and Breath Test for Evaluating Gastric Emptying}

Racol, a liquid nutrient formula containing $\left[1-{ }^{13} \mathrm{C}\right]$ acetic acid $(16 \mathrm{mg} / \mathrm{kg}$ ) was used as the test meal and administered orally in a volume of $2.5 \mathrm{~mL} / \mathrm{kg}$. The rat was placed in the chamber immediately after the oral administration of the test meal. The expired air was collected at 5-minute intervals for the first 70 minutes, with further samples taken at 90 and 120 minutes. The expired air was aspirated at a speed of $150 \mathrm{~mL} / \mathrm{min}$. At each sample point, the expired air was collected into a breath sampling bag for 1.5 minutes. A gaseous mixture of $5 \% \mathrm{CO}_{2}$ and $95 \% \mathrm{O}_{2}$ was used as the reference gas 
of the spectrometer. The ${ }^{13} \mathrm{CO}_{2}$ levels were measured by placing the breath-sampling bags into the inlet port of the spectrometer. The measured values are presented as $\Delta{ }^{13} \mathrm{CO}_{2}(\%)$.

The maximum concentration of ${ }^{13} \mathrm{CO}_{2}\left(\mathrm{C}_{\max }, \%\right.$ ) , the time taken to reach the maximum concentration $\left(\mathrm{T}_{\max }, \mathrm{min}\right)$, and the area under the curve $\left(\mathrm{AUC}_{120 \mathrm{~min}}\right.$ \% \% $\left.\mathrm{min}\right)$ were calculated using the measured $\Delta^{13} \mathrm{CO}_{2}$ values and used as pharmacokinetic parameters in addition to the change in the expired ${ }^{13} \mathrm{CO}_{2}$ as described in the previous manuscript. ${ }^{14}$

\section{Barostat Study}

Gastric adaptive relaxation was evaluated as we have previously described. ${ }^{15}$ In brief, rats were anesthetized by urethane $(1.2 \mathrm{~g} / \mathrm{kg}$, ip). For fitting the balloon to the fundus, a slightly improved balloon was obtained by removing the tube within the balloon. A polyvinyl tube with an adherent polyethylene bag (maximum volume $7 \mathrm{~mL}$; $3 \mathrm{~cm}$ maximum diameter) was introduced from the rat's mouth to its stomach. Five milliliters of air was injected into the balloon from one of the balloon tubes under the other-side balloon tube which was closed for fitting the balloon to the fundus, and the balloon tube was immediately opened to the air.

After 5 minutes of recovery time, the tube of the balloon was connected to the barostat (Barostat Distender IIR; G\&J Electronics, North York, ON, Canada). The pressure of the balloon was changed stepwise by $1,2,4$, and $8 \mathrm{mmHg}$ at 1 -minute intervals. The volume of the balloon was increased by the change of the pressure. The balloon volume just after the change of the pressure increased gradually and reached a plateau approximately 1 minute after the change of the pressure. The amplitude of the gradual component was used as the gastric adaptive relaxation

The gastric adaptive relaxation increased in a pressure-dependent manner and showed the highest value at $8 \mathrm{mmHg}$. The effects of amino acids are thus expressed as the percentage of the control at $8 \mathrm{mmHg}$.

After evaluation of gastric adaptive relaxation, we checked whether the balloon was positioned at the fundus or not. In cases in which the balloon was not in the right position, the data obtained were excluded from the analysis.

\section{Amino Acid Treatment}

We used a cyclic amino acid, ie, L-proline; 3 amino acids with an aromatic ring, ie, L-histidine, L-tyrosine, and L-phenylalanine; 2 amino acids with a sulfur group, ie, L-cysteine and L-methionine; 2 acidic amino acids, ie, L-aspartic aid and L-glutamic acid; and 4 basic amino acids, ie, L-asparagine, L-arginine, L-glutamine, and
L-lysine. After the rat was fasted for 18 hours, $1 \mathrm{~g} / \mathrm{kg}$ of each amino acid dissolved or suspended in distilled water for the injection was administered orally in a volume of $5 \mathrm{~mL} / \mathrm{kg}$. In the control rats, distilled water was administered instead of the amino acid for the injection. The breath test and barostat study were performed 30 minutes after the amino acid administration.

\section{Agents}

The amino acids were purchased from Wako Pure Chemical (Tokyo, Japan). $\left[1-{ }^{13} \mathrm{C}\right]$ acetic acid was purchased from Cambridge Isotope Laboratories (Cambridge, MA, USA). The Racol and the distilled water for the injection were obtained from Otsuka Pharmaceutical (Tokyo, Japan) and Otsuka Pharmaceutical (Tokushima, Japan), respectively.

\section{Statistical Methods}

All results are presented as the mean $\pm \mathrm{SD}$ or SEM. The statistical analysis was performed by Dunnett's multiple comparison test, and a $P$-value $<0.05$ was considered significant.

\section{Results}

\section{Effects of the Amino Acids on Gastric Emptying}

The changes of expired ${ }^{13} \mathrm{CO}_{2}$ air in the control rats and amino acid-treated rats are shown in Figures 1A and 2A. The effects of the amino acids on the pharmacokinetic parameters are given in Table. In the control group, the expired ${ }^{13} \mathrm{CO}_{2}$ air increased with time and peaked at approximately 30 minutes before decreasing (Fig. $1 \mathrm{~A}$ and $2 \mathrm{~A})$. The $\mathrm{C}_{\max }, \mathrm{T}_{\max }$, and $\mathrm{AUC}_{120 \min }$ values were $386.6 \pm 47.3 \%$, $28.8 \pm 4.8$ minutes, and $25665 \pm 1823 \% \circ \cdot \mathrm{min}$, respectively (Table). Compared with the values of $\mathrm{T}_{\max }, \mathrm{C}_{\max }$, and $\mathrm{AUC}_{120 \min }$ in the control group, there were no amino acids that significantly enhanced gastric emptying under the present experimental conditions (Table).

The effects of L-proline, L-histidine, L-tyrosine, L-phenylalanine, L-cysteine, and L-methionine are shown in Figure 1A. LProline, L-histidine, L-cysteine, and L-methionine significantly delayed and inhibited gastric emptying, because the $T_{\text {max }}$ was significantly delayed, the $\mathrm{C}_{\max }$ values were significantly decreased, and the $\mathrm{AUC}_{120 \mathrm{~min}}$ values were significantly decreased compared to the control (Table). Two of the amino acids with an aromatic ring, ie, L-Tyrosine and L-phenylalanine showed no influence on gastric emptying (Fig. 1A and Table).

The effects of the acidic and basic amino acids are shown in 

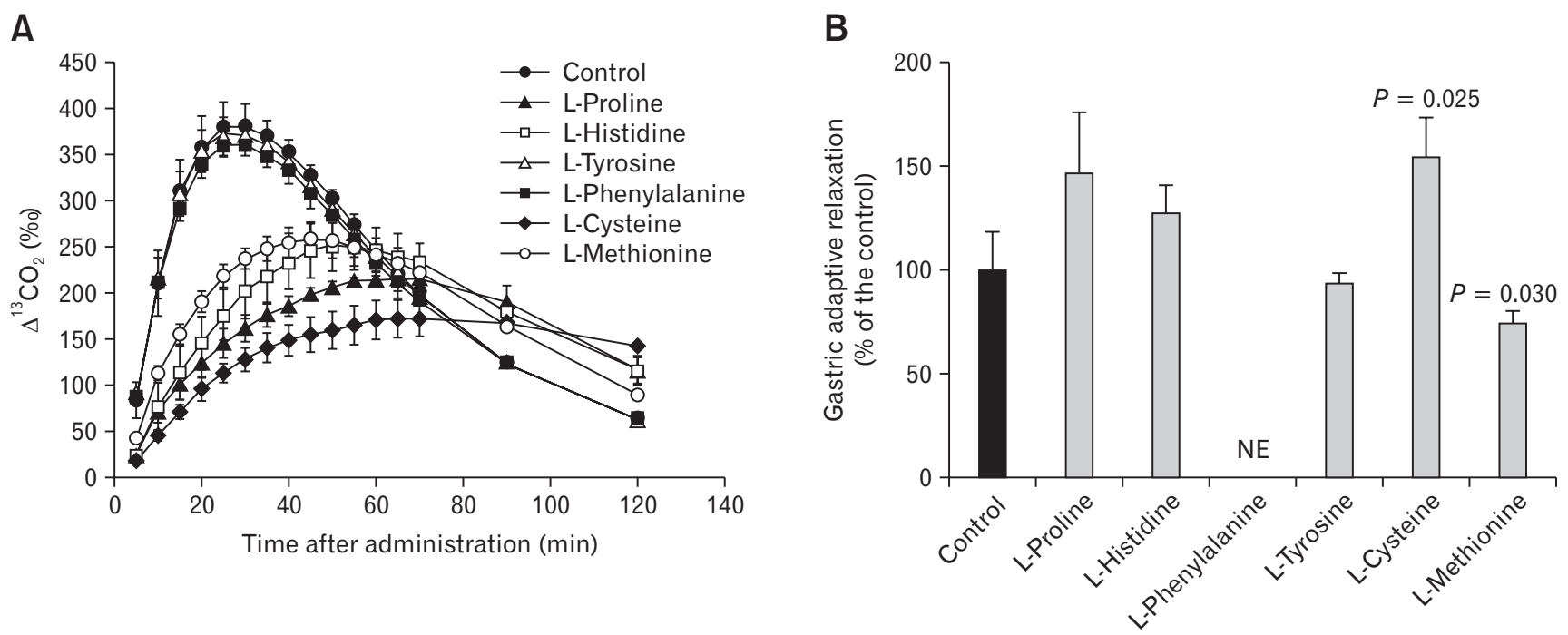

Figure 1. The effects of L-proline, L-histidine, L-tyrosine, L-phenylalanine, L-cysteine, and L-methionine on gastric emptying (A) and gastric adaptive relaxation $(B)$ in rats. Values are mean \pm SEM $(n=4$ in gastric emptying and $n=6$ in gastric adaptive relaxation). $P$-values represent the difference from controls. NE means not evaluated, because L-phenylalanine moved the balloon toward the antrum from the fundus in all rats used $(n=6)$.

A

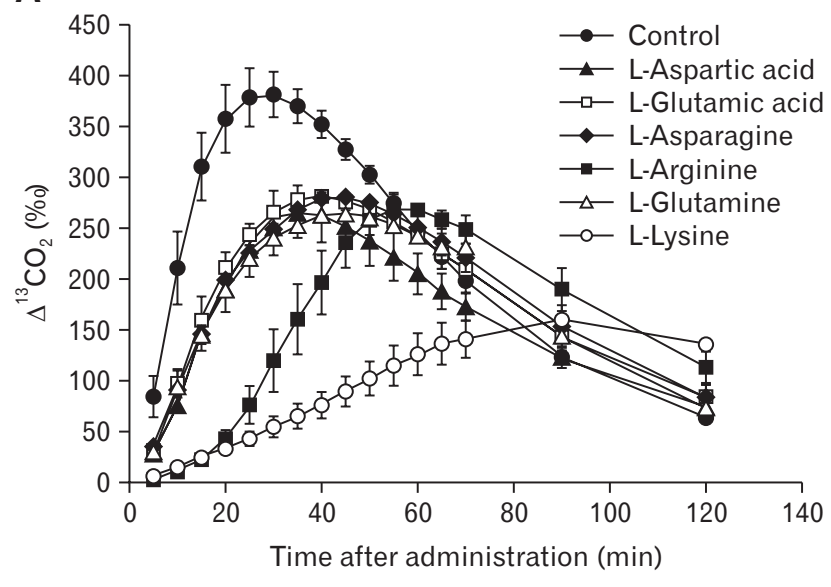

B

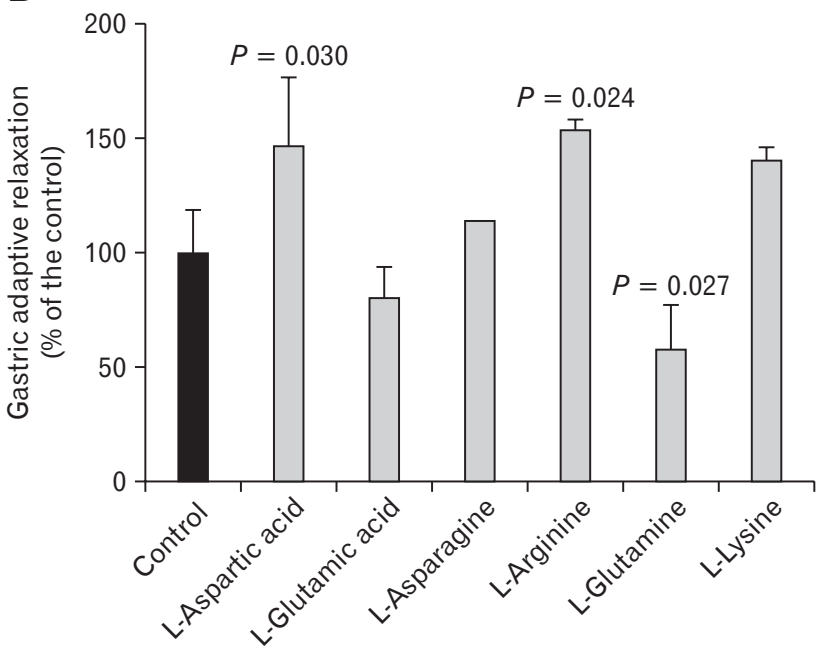

Figure 2. The effects of L-aspartic acid, L-glutamic acid, L-asparagine, L-arginine, L-glutamine, and L-lysine on the gastric emptying (A) and gastric adaptive relaxation $(B)$ in rats. Values are mean \pm SEM $(n=4$ in gastric emptying and $n=6$ in gastric adaptive relaxation). $P$-values represent the difference from controls.

Figure $2 \mathrm{~A}$ and summarized in Table. All of these amino acids significantly delayed and inhibited the gastric emptying, because the $\mathrm{T}_{\max }$ was significantly delayed, the $\mathrm{C}_{\max }$ values were significantly decreased, and the $\mathrm{AUC}_{120 \mathrm{~min}}$ values were significantly decreased compared with the control values (Table).

\section{The Effects of the Amino Acids on Gastric Adaptive Relaxation}

In the control group, the volume of gastric adaptive relaxation increased with the increase in the balloon pressure, and the gastric adaptive relaxation was $0.57 \pm 0.11 \mathrm{~mL}$ at $8 \mathrm{mmHg}$. The effects 
Table. The Effects of Amino Acids on the Pharmacokinetic Parameters of the Expired $\Delta^{13} \mathrm{CO}_{2}$ from Rats Treated with [1- $\left.{ }^{13} \mathrm{C}\right]$ Acetic Acid

\begin{tabular}{|c|c|c|c|}
\hline Treatment & $\mathrm{C}_{\max }(\% 0)$ & $\mathrm{T}_{\max }(\min )$ & $\mathrm{AUC}_{120 \min }(\% \cdot \mathrm{min})$ \\
\hline Control & $386.6 \pm 47.3$ & $28.8 \pm 4.8$ & $25665 \pm 1823$ \\
\hline L-Proline & $\begin{array}{r}222.5 \pm 23.5 \\
(P<0.001)\end{array}$ & $\begin{array}{c}58.8 \pm 7.5 \\
(P<0.001)\end{array}$ & $\begin{array}{r}19462 \pm 882 \\
(P<0.001)\end{array}$ \\
\hline L-Histidine & $\begin{array}{r}260.4 \pm 56.0 \\
(P=0.014)\end{array}$ & $\begin{array}{c}53.8 \pm 7.5 \\
(P<0.001)\end{array}$ & $\begin{array}{c}21337 \pm 2741 \\
(P=0.039)\end{array}$ \\
\hline L-Tyrosine & $379.5 \pm 24.5$ & $26.3 \pm 6.3$ & $25310 \pm 763$ \\
\hline L-Phenylalanine & $364.1 \pm 12.0$ & $26.7 \pm 5.8$ & $24657 \pm 635$ \\
\hline L-Cysteine & $\begin{array}{c}178.5 \pm 34.8 \\
(P<0.001)\end{array}$ & $\begin{array}{c}76.3 \pm 16.0 \\
(P<0.001)\end{array}$ & $\begin{array}{c}16439 \pm 2966 \\
(P=0.002)\end{array}$ \\
\hline L-Methionine & $\begin{array}{r}261.1 \pm 35.2 \\
(P=0.005)\end{array}$ & $40.0 \pm 9.1$ & $\begin{array}{c}21732 \pm 2281 \\
(P=0.036)\end{array}$ \\
\hline L-Aspartic acid & $\begin{array}{c}266.4 \pm 51.6 \\
(P<0.001)\end{array}$ & $\begin{array}{c}35.0 \pm 0.0 \\
(P=0.040)\end{array}$ & $\begin{array}{c}19251 \pm 2255 \\
(P=0.005)\end{array}$ \\
\hline L-Glutamic acid & $\begin{array}{c}283.0 \pm 5.3 \\
(P=0.005)\end{array}$ & $\begin{array}{c}38.3 \pm 2.9 \\
(P=0.029)\end{array}$ & $\begin{array}{r}21741 \pm 339 \\
(P=0.016)\end{array}$ \\
\hline L-Asparagine & $\begin{array}{c}282.1 \pm 4.4 \\
(P=0.014)\end{array}$ & $\begin{array}{c}43.3 \pm 2.9 \\
(P=0.006)\end{array}$ & $\begin{array}{r}21916 \pm 408 \\
\quad(P=0.019)\end{array}$ \\
\hline L- Arginine & $\begin{array}{r}280.4 \pm 14.9 \\
(P=0.005)\end{array}$ & $\begin{array}{c}57.5 \pm 10.4 \\
(P=0.002)\end{array}$ & $\begin{array}{l}9206 \pm 563 \\
(P=0.001)\end{array}$ \\
\hline L- Glutamine & $\begin{array}{c}270.4 \pm 9.6 \\
(P=0.003)\end{array}$ & $\begin{array}{c}45.0 \pm 7.1 \\
(P=0.009)\end{array}$ & $\begin{array}{r}20685 \pm 645 \\
(P=0.002)\end{array}$ \\
\hline L- Lysine & $\begin{array}{r}161.2 \pm 23.5 \\
(P<0.001)\end{array}$ & $\begin{array}{c}81.7 \pm 14.4 \\
(P<0.001)\end{array}$ & $\begin{array}{c}12327 \pm 2364 \\
(P<0.001)\end{array}$ \\
\hline
\end{tabular}

Values are the mean $\pm \mathrm{SD}$ of the rats $(\mathrm{n}=4)$. Values in parentheses indicate $P$-value vs control.

of the amino acids on gastric adaptive relaxation are illustrated in Figures $1 \mathrm{~B}$ and 2B. Compared to the control, L-cysteine, Laspartic acid, and L-arginine significantly enhanced gastric adaptive relaxation (Fig. $1 \mathrm{~B}$ and $2 \mathrm{~B}$ ). Conversely, L-methionine and Lglutamine significantly inhibited gastric adaptive relaxation (Fig. 1B and 2B). After we checked the position of the balloon, we observed that L-phenylalanine moved the balloon toward the antrum from the fundus in all rats $(\mathrm{n}=6)$. Therefore, the adaptive gastric relaxation by L-phenylalanine could not be calculated (Fig. 1B).

\section{The Correlation Between Gastric Emptying and Gastric Adaptive Relaxation}

In addition to the results obtained in the present study, we added the data that we obtained in previous studies of amino acids with a straight alkyl chain, hydroxylated chain, and branched chain, and L-tryptophan on the gastric emptying and gastric adaptive relation. $^{7-9}$ A significant positive correlation was observed between gastric adaptive relaxation and $\mathrm{T}_{\max }$ vlues $(r=0.709$, Fig. 3A). Significant negative correlations were also observed between gastric adaptive relation and $\mathrm{C}_{\max }$ and $\mathrm{AUC}_{120 \min }$ values $(r=0.613$, Fig.
3B; $r=0.667$, Fig. 3C, respectively).

\section{Amino Acids' Chemical Structure, Gastric Emptying, and Adaptive Relaxation}

The chemical structures of the amino acids and the results of gastric emptying and adaptive relaxation are shown in Figure 4. Of the aromatic amino acids, L-tyrosine and L-phenylalanine (which have a benzene ring) showed no effect on gastric emptying. However, L-proline (which has a pyrrole ring) and L-histidine (which has an imidazole ring) significantly delayed and inhibited gastric emptying, suggesting that the difference of the aromatic ring differently influences gastric emptying. Only L-phenylalanine did not inhibit gastric emptying.

Among the sulfur amino acids, L-cysteine (which has a shorter side chain) showed greater delay and inhibition of the gastric emptying compared to L-methionine (which has a longer side chain). Regarding the acidic amino acids, the length of the side chain did not show a significant difference between L-aspartic acid and Lglutamic acid. Of the basic amino acids, L-arginine and L-lysine (which have a longer side chain) showed greater delay and inhibi- 

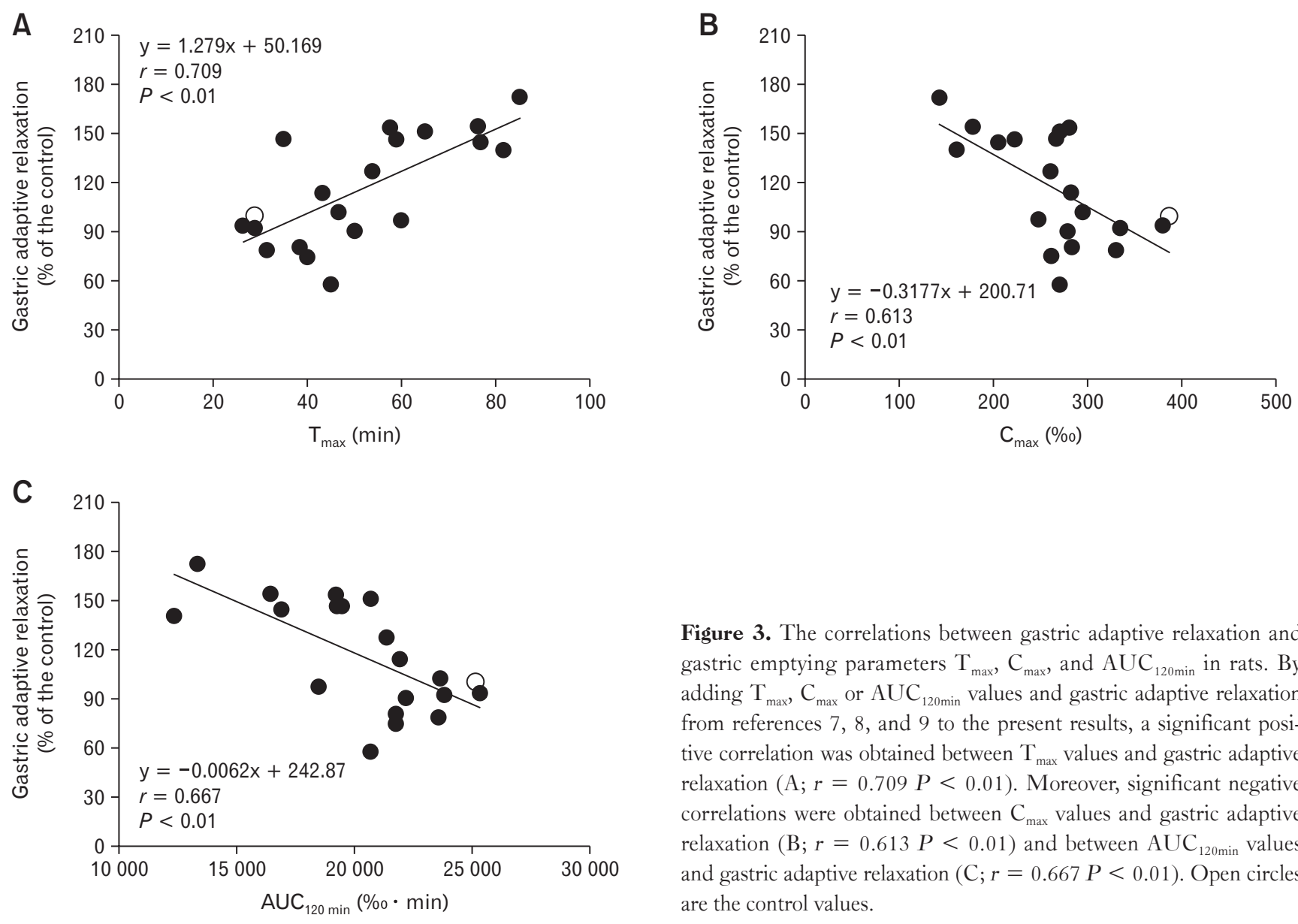

Figure 3. The correlations between gastric adaptive relaxation and gastric emptying parameters $\mathrm{T}_{\max }, \mathrm{C}_{\max }$, and $\mathrm{AUC}_{120 \min }$ in rats. $\mathrm{By}$ adding $\mathrm{T}_{\max }, \mathrm{C}_{\max }$ or $\mathrm{AUC}_{120 \min }$ values and gastric adaptive relaxation from references 7,8 , and 9 to the present results, a significant positive correlation was obtained between $\mathrm{T}_{\max }$ values and gastric adaptive relaxation $(\mathrm{A} ; r=0.709 P<0.01)$. Moreover, significant negative correlations were obtained between $\mathrm{C}_{\max }$ values and gastric adaptive relaxation $(\mathrm{B} ; r=0.613 P<0.01)$ and between $\mathrm{AUC}_{120 \mathrm{~min}}$ values and gastric adaptive relaxation $(\mathrm{C} ; r=0.667 \mathrm{P}<0.01)$. Open circles are the control values.

tion of the gastric emptying compared to L-asparagine and Lglutamine (which have a shorter side chain).

Regarding the gastric adaptive relaxation of the amino acids with an aromatic ring, only L-phenylalanine inhibited relaxation. Of the sulfur and acidic amino acids, L-cysteine and L-aspartic acid (which have a shorter side chain) showed enhanced gastric adaptive relaxation compared to L-methionine and L-glutamine (which have a longer side chain). Among the basic amino acids, Larginine and L-lysine (which have a longer side chain) enhanced the gastric adaptive relaxation more than L-asparagine, which did not show a marked effect on gastric adaptive relaxation. In contrast, L-glutamine showed a marked inhibitory effect on gastric adaptive relaxation.

\section{Discussion}

Concerning the effects of amino acids on gastric emptying, there are many reports. In the present study, many amino acids were

found to influence gastric emptying. However, L-phenylalanine did not significantly delay and inhibit gastric emptying. Indeed, L-phenylalanine, a potent cholecystokinin (CCK) releaser, did not slow gastric emptying in dogs, ${ }^{4}$ which supports our present findings. On the contrary, L-phenylalanine released CCK and was associated with reduced food intake in humans. ${ }^{16}$ L-Proline (a cyclic amino acid) and L-histidine which have a 5-membered ring delayed and inhibited gastric emptying. However, L-phenylalanine and L-tyrosine did not influence gastric emptying. Amino acids with a 6-membered aromatic ring may thus have no effect on gastric emptying. Regarding the sulfur amino acids, L-methionine and L-cysteine significantly delayed and inhibited gastric emptying. On the contrary, DL-methionine did not influence gastric emptying in young pigs ${ }^{17}$ and L-methionine did not influence gastric emptying in dogs. ${ }^{4}$ In this study, L-cysteine significantly delayed and inhibited gastric emptying. L-Cysteine suppressed ghrelin and reduced appetite in both rodents and humans, ${ }^{18}$ suggesting the inhibition of gastric emptying. Therefore, the ghrelin may explain the mecha- 
Cyclic amino acid<smiles>O=C(O)C1CCCN1</smiles>

L-Proline

\begin{tabular}{|l|r|}
\hline $\begin{array}{l}\text { Adaptive } \\
\text { relaxation (\%) }\end{array}$ & 146.5 \\
\hline $\mathrm{C}_{\max }(\% \circ)$ & 222.5 \\
\hline $\mathrm{T}_{\max }(\min )$ & 58.8 \\
\hline $\begin{array}{l}\mathrm{AUC} \mathrm{C}_{120 \min } \\
(\% 0 \cdot \min )\end{array}$ & 19462 \\
\hline
\end{tabular}

Aromatic amino acid<smiles>N[C@@H](Cc1c[nH]cn1)C(=O)O</smiles>

\begin{tabular}{|l|r|}
\hline $\begin{array}{l}\text { Adaptive } \\
\text { relaxation (\%) }\end{array}$ & 127.2 \\
\hline $\mathrm{C}_{\max }(\% 0)$ & 260.4 \\
\hline $\mathrm{T}_{\max }(\min )$ & 26.7 \\
\hline $\begin{array}{l}\mathrm{AUC} \mathrm{C}_{120 \min } \\
(\% 0 \cdot \min )\end{array}$ & 21337 \\
\hline
\end{tabular}<smiles>N[C@@H](Cc1ccccc1)C(=O)O</smiles>

L-Phenylalanine

\begin{tabular}{|l|r|}
\hline $\begin{array}{l}\text { Adaptive } \\
\text { relaxation (\%) }\end{array}$ & NE \\
\hline $\mathrm{C}_{\max }(\%)$ & 364.1 \\
\hline $\mathrm{T}_{\max }(\mathrm{min})$ & 26.7 \\
\hline $\begin{array}{l}\mathrm{AUC} \mathrm{C}_{120 \min } \\
(\% \cdot \cdot \mathrm{min})\end{array}$ & 24657 \\
\hline
\end{tabular}

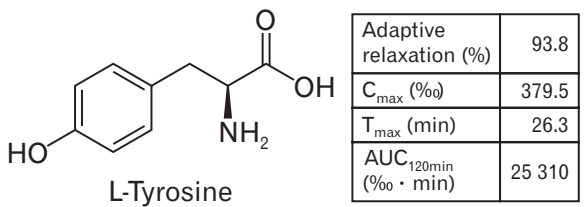

Sulfur amino acid<smiles>NC(CS)C(=O)O</smiles>

\begin{tabular}{|l|r|}
\hline $\begin{array}{l}\text { Adaptive } \\
\text { relaxation (\%) }\end{array}$ & 154.1 \\
\hline $\mathrm{C}_{\max }(\% 0)$ & 178.5 \\
\hline $\mathrm{T}_{\max }(\mathrm{min})$ & 76.3 \\
\hline $\begin{array}{l}\mathrm{AUC}_{120 \min } \\
(\% 0 \cdot \min )\end{array}$ & 16439 \\
\hline
\end{tabular}<smiles>CSCC[C@H](N)C(=O)O</smiles>

\begin{tabular}{|l|r|}
\hline $\begin{array}{l}\text { Adaptive } \\
\text { relaxation (\%) }\end{array}$ & 74.8 \\
\hline $\mathrm{C}_{\max }(\% 0)$ & 261.2 \\
\hline $\mathrm{T}_{\max }(\min )$ & 40 \\
\hline $\begin{array}{l}\mathrm{AUC}_{120 \min } \\
(\% 0 \cdot \min )\end{array}$ & 21732 \\
\hline
\end{tabular}

Acidic amino acid<smiles>N[C@@H](CC(=O)O)C(=O)O</smiles>

L-Aspartic acid

\begin{tabular}{|l|r|}
\hline $\begin{array}{l}\text { Adaptive } \\
\text { relaxation (\%) }\end{array}$ & 146.8 \\
\hline $\mathrm{C}_{\max }(\% 0)$ & 266.4 \\
\hline $\mathrm{T}_{\max }(\min )$ & 35 \\
\hline $\begin{array}{l}\mathrm{AUC}_{120 \min } \\
(\% 0 \cdot \min )\end{array}$ & 19251 \\
\hline
\end{tabular}<smiles>N[C](CCC(=O)O)C(=O)O</smiles>

L-Glutamic acid

\begin{tabular}{|l|r|}
\hline $\begin{array}{l}\text { Adaptive } \\
\text { relaxation (\%) }\end{array}$ & 80.5 \\
\hline $\mathrm{C}_{\max }(\% \circ)$ & 283 \\
\hline $\mathrm{T}_{\max }(\min )$ & 38.3 \\
\hline $\begin{array}{l}\mathrm{AUC} \\
\left(\% \mathrm{C}_{120 \min }\right. \\
(\% \circ \min )\end{array}$ & 21741 \\
\hline
\end{tabular}

Basic amino acid<smiles>NC(=O)C[C@H](N)C(=O)O</smiles>

L-Asparagine<smiles>N=C(N)NCCC[C@H](N)C(=O)O</smiles>

L-Arginine

\begin{tabular}{|l|r|}
\hline $\begin{array}{l}\text { Adaptive } \\
\text { relaxation (\%) }\end{array}$ & 114 \\
\hline $\mathrm{C}_{\max }(\%)$ & 282.1 \\
\hline $\mathrm{T}_{\max }(\min )$ & 43.3 \\
\hline $\begin{array}{l}\mathrm{AUC} \mathrm{C}_{120 \min } \\
(\% \circ \cdot \min )\end{array}$ & 21916 \\
\hline
\end{tabular}

\begin{tabular}{|l|r|}
\hline $\begin{array}{l}\text { Adaptive } \\
\text { relaxation (\%) }\end{array}$ & 153.5 \\
\hline $\mathrm{C}_{\max }(\%)$ & 280.4 \\
\hline $\mathrm{T}_{\max }(\min )$ & 57.5 \\
\hline $\begin{array}{l}\mathrm{AUC}_{120 \min } \\
(\% \circ \cdot \min )\end{array}$ & 19206 \\
\hline
\end{tabular}<smiles>NC(=O)CC[C@H](N)C(=O)O</smiles>

L-Glutamine<smiles>NCCCC[C@H](N)C(=O)O</smiles>

\begin{tabular}{|l|r|}
\hline $\begin{array}{l}\text { Adaptive } \\
\text { relaxation (\%) }\end{array}$ & 57.8 \\
\hline $\mathrm{C}_{\max }(\%)$ & 270.4 \\
\hline $\mathrm{T}_{\max }(\mathrm{min})$ & 45 \\
\hline $\begin{array}{l}\mathrm{AUC} \mathrm{C}_{120 \min } \\
(\% \circ \cdot \min )\end{array}$ & 20685 \\
\hline
\end{tabular}

\begin{tabular}{|l|r|}
\hline $\begin{array}{l}\text { Adaptive } \\
\text { relaxation (\%) }\end{array}$ & 140.2 \\
\hline $\mathrm{C}_{\max }(\%)$ & 161.2 \\
\hline $\mathrm{T}_{\max }(\mathrm{min})$ & 81.7 \\
\hline $\begin{array}{l}\mathrm{AUC} \mathrm{C}_{120 \min } \\
(\% \circ \cdot \mathrm{min})\end{array}$ & 12327 \\
\hline
\end{tabular}

Figure 4. The chemical structures of the amino acids and their effects on the gastric emptying and gastric adaptive relaxation. NE means not evaluated, because L-phenylalanine moved the balloon toward the antrum from the fundus in all rats used $(\mathrm{n}=6)$. nism of L-cysteine.

On the L-glutamine, significant delay and inhibition was observed. Glutamine was found to be a novel agent for increasing the glucagon-like peptide- $1,{ }^{19}$ which inhibits gastric emptying. ${ }^{20}$ This finding supports our present results. However, no effect was found on antral, duodenal or pyloric pressures or plasma CCK in healthy men. ${ }^{21}$ L-Arginine and L-Asparagine also significantly delayed and inhibited gastric emptying. These amino acids had a direct sensory input assessing dietary protein content and quality. ${ }^{5} \mathrm{~L}$-Lysine dosedependently delayed gastric emptying and stimulated gastrointestinal secretion in rats, ${ }^{22}$ in accordance with our present results, but not in young pigs. ${ }^{18}$ In a dog model, aspartic acid did not influence gastric emptying, ${ }^{4}$ but in this study it inhibited and delayed gastric emptying. Food intake was most potently reduced by oral Lglutamic acid in rats, ${ }^{5}$ and also in a clinical study, monosodium glutamate increased antral distension, ${ }^{23}$ supporting our present 
results. However, these conflicting results may be due to the differences in experimental conditions. Indeed, some amino acids mentioned above supported our results. However, the other amino acids showed opposite effects. Therefore, it would be very important to evaluate all amino acids by using the same experimental conditions at the same time, as we did in the present study. From the present study, it became newly obvious that L-proline and L-histidine significantly delayed and inhibited, and L-tyrosine did not influence gastric emptying.

Basic research using rats investigated the intra-gastric pressure by inserting a pressure transducer into the stomach via a surgical procedure. ${ }^{24,25}$ However, it is easy to speculate that such a surgical procedure affects the gastric physiological function in an animal study, and that an animal study does not always reflect in vivo and human physiology. We improved the method for investigating gastric adaptive relaxation with the use of a barostat without the need for a surgical procedure, ${ }^{15}$ and used this method in the present study. Adaptive relaxation has been known to be mediated by the capsaicin-sensitive afferent nerve. The acute administration of capsaicin decreased the proximal gastric tone and inhibited the phasic contractility of the proximal stomach in humans. ${ }^{26}$ We also reported that nitric oxide (NO) plays an important role in the gastric adaptive relaxation as demonstrated with the use of a barostat. ${ }^{15}$ Indeed, $\mathrm{NO}$ formed from L-arginine was detected in the murine stomach in vivo. ${ }^{27}$ In the present study, L-cysteine, L-aspartic acid and Larginine significantly enhanced the gastric adaptive relaxation. We therefore speculate that L-arginine enhances the gastric adaptive relaxation through NO generation. However, the mechanisms underlying the effects of L-cysteine and L-aspartic acid on enhanced gastric adaptive relaxation remain unclear. In contrast, L-methionine and L-glutamine significantly inhibited gastric adaptive relaxation in our present investigation. L-Phenylalanine moved the balloon to the antrum, suggesting a strong contraction of the fundus.

In this study, we analyzed the correlation between gastric emptying and gastric adaptive relaxation by adding the data obtained in our earlier studies. ${ }^{7-9}$ A significant positive correlation was then revealed between gastric adaptive relaxation and the $T_{\max }$ values. Significant negative correlations were also observed between gastric adaptive relaxation and the $\mathrm{C}_{\max }$ values and $\mathrm{AUC}_{120 \min }$. These data clearly indicate that gastric emptying has a close relationship with gastric adaptive relaxation.

Diet therapy and exercise therapy are therapeutic methods for obesity, ${ }^{28}$ but these therapies do not always provide sufficient effects. Partial gastric resection and various other surgical procedures are thus sometimes used to combat obesity. ${ }^{29}$ The goal of such surgical operations is to decrease the volume of food ingested by a patient by decreasing the stomach volume. In this study, L-glutamine, L-methionine, and L-phenylalanine inhibited gastric adaptive relaxation and L-phenylalanine had the most potent activity, suggesting that these amino acids may be useful for treating obesity. Lphenylalanine in particular may be the most useful amino acid for this purpose, because L-phenylalanine does not influence gastric emptying, and the inhibition of gastric emptying may cause bloating. On the other hand, dysfunction of gastric adaptive relaxation is closely related to the pathogenesis of early satiety, and the improvement of gastric adaptive relaxation could thus be a useful therapy for functional dyspepsia. ${ }^{30}$ In the present study, L-aspartic acid significantly enhanced gastric adaptive relaxation in the rat model, and L-aspartic acid did not markedly influence gastric emptying, showing that L-aspartic acid does not induce gastric bloating. Therefore, L-aspartic acid may become a useful agent for the therapy of functional dyspepsia, especially its feature of early satiety.

In conclusion, we observed a significant positive correlation between enhanced gastric adaptive relaxation and inhibition of gastric emptying evaluated by a breath test, suggesting that enhanced gastric adaptive relaxation delays gastric emptying. In addition, it was found that L-aspartic acid enhanced and L-glutamine, L-methionine, and L-phenylalanine inhibited gastric adaptive relaxation.

\section{Financial support: None.}

\section{Conflicts of interest: None.}

Author contributions: Masayuki Uchida designated the study, contributed to the data analysis and interpretation, and wrote the manuscript; and Orie Kobayashi and Chizuru Saito contributed to the study and the writing of the manuscript.

\section{References}

1. Young VR, Ajami AM. Glutamate: an amino acid of particular distribution. J Nutr 2000;130(4S suppl):892S-900S.

2. Uematsu A, Tsurugizawa T, Kondoh T, Torii K. Conditioned flavor preference learning by intragastric administration of $\mathrm{L}$-glutamate in rats. Neurosci Lett 2009;451:190-193.

3. Torii K, Uneyama H, Nakamura E. Physiological roles of dietary glutamate signaling via gut-brain axis due to efficient digestion and absorption. J Gastroenterol 2013;48:442-451.

4. Stephens JR, Woolson RF, Cooke AR. Effects of essential and nonessential amino acids on gastric emptying in the dog. Gastroenterology 1975;69:920-927.

5. Jordi J, Herzog B, Camargo SM, Boyle CN, Lutz TA, Verrey F. Specif- 
ic amino acids inhibit food intake via the area postrema or vagal afferents. J Physiol 2013;591:5611-5621.

6. Carney BI, Jones KL, Horowitz M, Sun WM, Hebbard G, Edelbroek MA. Stereospecific effects of tryptophan on gastric emptying and hunger in humans. J Gastroenterol Hepatol 1994;9:557-563.

7. Uchida M, Kobayashi O, Iwasawa K, Shimizu K. Effects of straight alkyl chain, extra hydroxylated alkyl chain and branched chain amino acids on gastric emptying evaluated using a non-invasive breath test in conscious rats. J Smooth Muscle Res 2016;52:36-44.

8. Uchida $\mathrm{M}$, Iwamoto $\mathrm{C}$. Influence of amino acids on the gastric adaptive relaxation (accommodation) evaluated by barostat. J Smooth Muscle Res 2016;52:56-65.

9. Uchida M, Kobayashi O, Iwamoto C. Effects of L-tryptophan on gastric emptying evaluated by breath test in relation to gastric accommodation evaluated by barostat in rats. J Pharmacol Sci 2015;127:229-231.

10. Sanaka M, Yamamoto T, Kuyama Y. Effects of proton pump inhibitors on gastric emptying: a systematic review. Dig Dis Sci 2010;55:24312440 .

11. Verschueren S, Janssen P, Van Oudenhove L, Hultin L, Tack J. Effect of pancreatic polypeptide on gastric accommodation and gastric emptying in conscious rats. Am J Physiol Gastrointest Liver Physiol 2014;307:G122G128.

12. Matsueda K, Hongo M, Tack J, Aoki H, Saito Y, Kato H. Clinical trial: dose-dependent therapeutic efficacy of acotiamide hydrochloride (Z-338) in patients with functional dyspepsia - $100 \mathrm{mg}$ t.i.d. is an optimal dosage. Neurogastroenterol Motil 2010;22:618-e173.

13. Tack J, Janssen P. Acotiamide (Z-338, YM443), a new drug for the treatment of functional dyspepsia. Expert Opin Investig Drugs 2011;20:701712 .

14. Uchida M, Endo N, Shimizu K. Simple and noninvasive breath test using $13 \mathrm{C}$-acetic acid to evaluate gastric emptying in conscious rats and its validation by metoclopramide. J Pharmacol Sci 2005;98:388-395.

15. Uchida M, Shimizu K. Evaluation of adaptive relaxation of the rat stomach using an orally inserted balloon instead of surgical intervention by demonstrating the effects of capsaicin and $N^{\omega}$-nitro-L-arginine methylester. J Smooth Muscle Res 2012;48:97-104.

16. Ballinger AB, Clark ML. L-phenylalanine releases cholecystokinin $(\mathrm{CCK})$ and is associated with reduced food intake in humans: evidence for a physiological role of CCK in control of eating. Metabolism 1994;43:735-738.

17. Ochia BA. Influence of amino acids on gastric emptying in young pigs.
Acta Physiol Acad Sci Hung 1976;48:41-50

18. McGavigan AK, O'Hara HC, Amin A, et al. L-cysteine suppresses ghrelin and reduces appetite in rodents and humans. Int J Obes (Lond) 2015;39:447-455.

19. Samocha-Bonet D, Wong O, Synnott EL, et al. Glutamine reduces postprandial glycemia and augments the glucagon-like peptide-1 response in type 2 diabetes patients. J Nutr 2011;141:1233-1238.

20. Hellström PM, Näslund E, Edholm T, et al. GLP-1 suppresses gastrointestinal motility and inhibits the migrating motor complex in healthy subjects and patients with irritable bowel syndrome. Neurogastroenterol Motil 2008;20:649-659.

21. Steinert RE, Landrock MF, Horowitz M1, Feinle-Bisset C. Effects of intraduodenal infusions of L-phenylalanine and L-glutamine on antropyloroduodenal motility and plasma cholecystokinin in healthy men. J Neurogastroenterol Motil 2015;21:404-413.

22. Baruffol C, Jordi J, Camargo S, et al. L-lysine dose dependently delays gastric emptying and increases intestinal fluid volume in humans and rats. Neurogastroenterol Motil 2014;26:999-1009.

23. Boutry C, Matsumoto $\mathrm{H}$, Airinei $\mathrm{G}$, et al. Monosodium glutamate raises antral distension and plasma amino acid after a standard meal in humans. Am J Physiol Gastrointest Liver Physiol 2011;300:G137-G145.

24. Desai KM, Zembowicz A, Sessa WC, Vane JR. Nitroxergic nerves mediate vagally induced relaxation in the isolated stomach of the guinea pig. Proc Natl Acad Sci USA 1991;88:11490-11494.

25. Hayakawa T, Arakawa T, Kase Y, et al. Liu-Jun-Zi-Tang, a kampo medicine, promotes adaptive relaxation in isolated guinea pig stomachs. Drugs Exp Clin Res 1999;25:211-218.

26. Lee KJ, Vos R, Tack J. Effects of capsaicin on the sensorimotor function of the proximal stomach in humans. Aliment Pharmacol Ther 2004;19:415-425.

27. Mikoian VD, Kubrina LN, Vanin AF. [Detection of nitric oxide formed from L-arginine in the murine stomach in vivo by EPR.] Biofizika 1994;39:919-922. [Russian]

28. Bray GA, Frühbeck G, Ryan DH, Wilding JP. Management of obesity. Lancet 2016;387:1947-1956.

29. Jerraya H, Khalfallah M, Nouira R, Dziri C. "Gastric bypass" or "sleeve gastrectomy" for morbid obesity: a systematic review. Tunis Med 2015;93:585-589.

30. Fukudo S, Kuwano H, Miwa H. Management and pathophysiology of functional gastrointestinal disorders. Digestion 2012;85:85-89. 